Article

\title{
Does High-Speed Railway Influence Convergence of Urban-Rural Income Gap in China?
}

\author{
Weidong $\mathrm{Li}^{1}{ }^{1}$, Xuefang Wang ${ }^{1}$ and Olli-Pekka Hilmola ${ }^{2, *}$ \\ 1 School of Economics and Management, Beijing Jiaotong University, Beijing 100044, China; \\ wdli@bjtu.edu.cn (W.L.); $18120729 @ b j t u . e d u . c n(X . W$. \\ 2 Industrial Engineering and Management, LUT Kouvola, LUT University, Prikaatintie 9, \\ FIN-45100 Kouvola, Finland \\ * Correspondence: olli-pekka.hilmola@lut.fi; Tel.: +358-40-761-4307
}

Received: 27 March 2020; Accepted: 18 May 2020; Published: 21 May 2020

\begin{abstract}
Transportation is an important factor affecting the balance of regional economic pattern. The construction of high-speed railway enhances the mobility of population, capital, technology and information resources between urban and rural areas. Will it further affect the income gap between urban and rural areas? Based on the nonlinear time-varying factor model, this paper analyzes the convergence of urban-rural income gap with the angle of high-speed railway. After rejecting the assumption of overall convergence in the traditional four economic regions, three convergence clubs of urban-rural income gap were found. For these ordered logit regression model is used to explore the initial factors that may affect the formation of "convergence club". Empirical results show that the construction of High-speed railway has effectively narrows the urban-rural income gap in China, but it is not the cause of the formation of the three convergence clubs. The convergence effect of High-speed railway on the urban-rural income gap in China is still relatively weak.
\end{abstract}

Keywords: high-speed railway; income gap; club convergence; nonlinear time-varying factor model

\section{Introduction}

Since the reform and opening up, China's economy has maintained rapid growth. The income level of residents in urban and rural areas also has increased significantly. In recent years, China's urban-rural income gap has shown a long-term gradual decline, but in absolute terms, it is still substantial. According to the National Bureau of Statistics, the disposable income ratio of urban and rural residents in China during 2017 was 2.71:1 [1]. Although it has declined compared with previous years, it is still one of the important factors that constraints China's economic development. In 2014, China's economic development has entered a new normal era. Under the background of the new economic development in the future, China's economic development will pay more attention to structural adjustment, regional development and income distribution. Under the grim situation of China's urban-rural income gap, it is debated how to find a solution. Approaching this gap is an important issue of concern to academics and government.

Due to the complexity of economic development and the variability of social conditions, there are many factors affecting the income gap between urban and rural areas. In the past decade, China's high-speed railway has developed rapidly. Chen et al. (2018) used high-speed rail parking frequency data in 274 cities in China from 2007 to 2014 to examine the impact of high-speed rail development on the income gap between urban and rural residents. The research results show that the development of high-speed rail is generally conducive to the narrowing of the income gap between urban and rural residents in China. Moreover, population flow and capital flow are important mechanisms for 
the development of high-speed rail to narrow the income gap between urban and rural residents in China [2].

Does high-speed railway affect the income gap between urban and rural areas to form a convergence club? The research goal of this paper is to evaluate the impact of the opening of high-speed railway on urban-rural income gap based on club convergence and deeply analyze the mechanism of high-speed railway's economic convergence effect on urban-rural income gap. The high-speed railway is both capital-intensive and labor-intensive large-scale transportation infrastructure. Its investment in construction and operation can have a profound impact on social and economic activities. The purpose of this paper is to find the convergence characteristics of urban-rural income gap under high-speed rail network situation. The contributions of the paper are as follows. At first, the paper firstly discusses the impact of the opening of high-speed railway on club convergence of urban-rural income gap in China with the nonlinear time-varying factor model. Secondly, three convergence clubs of urban-rural income gap in China are found. Thirdly, it is found that the construction of High-speed railway has effectively narrows the urban-rural income gap in China, but it is not the cause of the formation of the three convergence clubs. The convergence effect of High-speed railway on the urban-rural income gap in China is still relatively weak. It will enrich the impact of traffic on regional balance development. At the same time, it provides reference for alleviating the income gap between urban and rural areas in China. It also provides a policy basis for the implementation of regional balanced development strategy.

The rest of this research is organized as follows: In Section 2 we provide literature review follows, and Section 3 describes heterogeneity of urban-rural income gap within China's cities. The convergence club identification is being introduced in Section 4 . The causes of convergence club are discussed in Section 5. Finally, conclusions are drawn in Section 6.

\section{Literature Review}

High-speed rail is a type of rail transport that operates significantly faster than traditional rail traffic. New lines in excess of $250 \mathrm{~km} / \mathrm{hr}$ and existing lines in excess of $200 \mathrm{~km} / \mathrm{hr}$ are considered to be high-speed rail [3]. High-speed railway has brought great impact on many aspects of social \& economic life. Many scholars have conducted numerous research works on the influence of HSR. Zhang, et al., and Chai, et al. focus on the impact of HSR on aviation [4-6]. Li, et al., and Vickerman, et al. Discuss on the impact of HSR on economic growth [7-16]. Besides, some scholars pay attention to the social impact of HSR $[17,18]$. Chen et al., and Jiang, et al. take explorative analysis on the impact of HSR on regional income disparities and found that HSR can accelerate regional economic convergence and reduce the regional income disparities $[19,20]$.

With regard to the urban-rural income gap, Chinese scholars have carried out many constructive studies on this theme. The researches mainly focus on the status quo of urban-rural income gap, analysis of its causes, measurement and convergence issues In the related research on the convergence of urban-rural income gap, Wang et al. (2016) used the panel data of 71 counties in Wuling Mountain District from 2000 to 2012 to empirically examine the urbanization process, financial development and financial expenditure. Other factors promote the convergence of urban-rural income gap [21]. Deng (2016) used Hansen's panel threshold model to construct a nonlinear panel threshold model using China's 1997-2014 provincial panel data to study the impact of urbanization and industrialization on urban-rural income gap [22]. Song and Wang (2018) used data in 262 prefecture-level cities from 2000 to 2016 to explore the dynamic convergence of urban-rural income gap from the perspective of urban scale and analyze the influences of urban-rural income gap between population migration and household registration [23]. Wu (2019) used panel data from 1999 to 2017 in 30 provinces in China to construct a convergence model between government investment and urban-rural income gap. Research shows that the convergence of government investment structure promotes the convergence of urban and rural income gaps. Therefore, preventing government investment from being too fast can effectively reduce the urban-rural income gap [24]. Xu and Zhang (2019) used panel data from 30 provinces other than Tibet in China from 2000 to 2016 to analyze the dynamic evolution of China's 
urbanization and urban-rural income gap. The spatial and temporal effects of new urbanization on China's urban-rural income gap are also discussed. The study clarifies whether the transformation of urbanization can promote the convergence of the urban-rural income gap in China [25]. Besides China, some scholars conduct research on club convergence about income in other regions. Bartkowska, M., \& Riedl, A. (2012) used two-step method and ordered logit model to analyze convergence clubs in per capita incomes of European regions. It is found European regions form six separate groups converging to their own steady state paths. The level of initial conditions such as human capital and per capita income plays a crucial role in determining the formation of convergence clubs among European regions [26]. Canova, F. (2004) developed a predictive density approach to identify convergence clubs in Organization for Economic Co-operation and Development (OECD) countries [27]. Galor, O. (2007) used Unified Growth Theory to explain the emergence of convergence clubs [28].

In the study of the convergence of urban-rural income gap, most scholars focus on the impact of urbanization, population migration, regional economic growth, human capital and other factors on the convergence of urban-rural income gap [29-38]. However, the impact of high-speed rail on the convergence of urban-rural income gap has not yet been discussed. The research will shed some light on the understanding of how HSR influence the convergence of urban-rural income gap. The research results can provide reference for investment construction of high-speed rail and narrowing the income gap between urban and rural areas in China.

\section{Heterogeneity of Urban-Rural Income Gap in China's Cities}

The factors affecting the income gap between urban and rural areas arise from many aspects such as nature, economy, society and culture [39-41]. Consumption expenditure ratio of urban and rural residents, urbanization level, population migration, regional economic growth and human capital are all important factors affecting the income gap between urban and rural areas. Based on the feasibility of data collection, we first calculate the mean and coefficient of variation of the urban-rural income gap of 274 prefecture-level cities in China (see Figure 1). The ratio of the per capita disposable income of urban residents to the per capita disposable income of rural residents is used as a measure of the income gap between urban and rural areas. The selected research period is from 2005 to 2017. The data are collected from the China Regional Statistical Yearbook and China's City Statistical Yearbook.

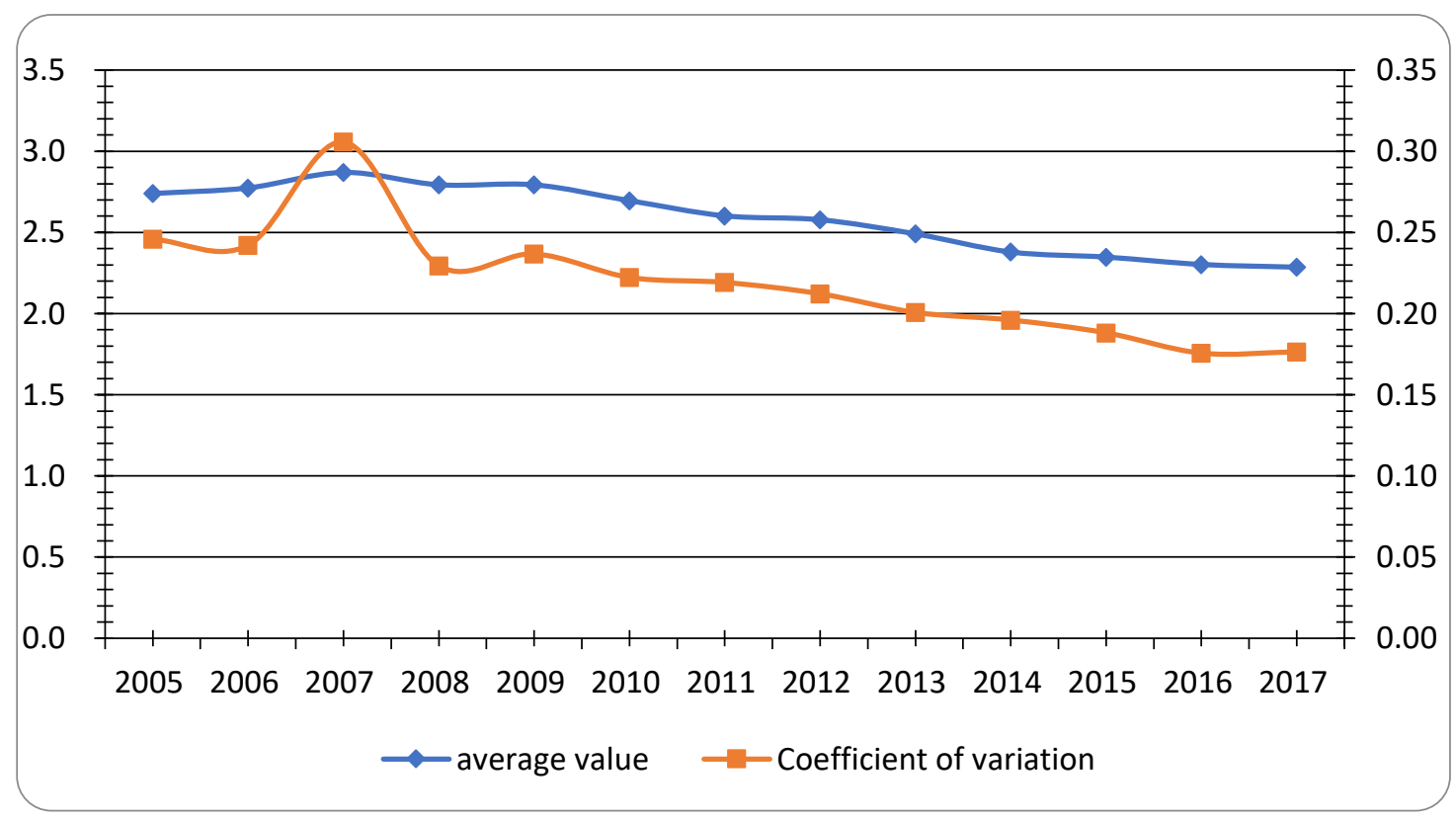

Figure 1. Mean and coefficient of variation of urban-rural income gap in 274 administrative regions in China. 
From Figure 1 it can be identified the average income gap between urban and rural areas that the urban-rural income gap in China continued to grow before 2007. However, it has showed clear downward trend thereafter. In terms of the difference in urban-rural income gap, the coefficient of variation is an indicator reflecting $\sigma$ convergence. The larger the value, the higher the dispersion of urban-rural income gap among cities. The trend of coefficient of variation of urban-rural income gap in prefecture-level cities in China has experienced a process of increasing first and then decreasing. The coefficient of variation reached its highest value in 2007. It shows that the difference in urban-rural income gap between cities shows a process of $\sigma$ convergence.

\section{Convergence Club Identification}

The basic concept of convergence came first from Solow's neoclassical growth model (Solow, 1956), starting with Baumol (1986) [42,43]. It has been used in different economic processes involving groups of regions or units. Generally there are three types of convergence: $\beta$-convergence, $\sigma$ convergence and club convergence. $\beta$-convergence implies that the units analyzed converge to one another in the long run. $\sigma$ convergence implies convergence that is conditional on the units having similar characteristics. Club convergence means that a set of economies with similar conditions and structural characteristics will tend to converge to the same steady state [44]. Phillips and Sul (2007) proposed the concept of relative convergence, which considers the transition path of each country together with its growth performance to find convergence [44].This concept can be easily extended to the field of convergence in income gap.

\subsection{Club Convergence Test Method Based on Nonlinear Time-Varying Factor Model}

This paper first explains the logt test method based on nonlinear time-varying factor model [45]. Then the paper gives the steps to identify the convergence club according to the logt test method. The identification steps of the convergence club was obtained by simplifying on the basis of Phillips and Sul (2007) [44].

\subsubsection{Logt Test}

At first a simple factor model is built as follows:

$$
X_{i t}=\delta_{i} \mu_{t}+\epsilon_{i t}
$$

The model is designed to capture the evolution of individual $X_{i t}$ with respect to $\mu_{t}$ under the influence of two heterogeneity factor system terms $\delta_{i}$ and error term $\varepsilon i t$. Among them, $\delta_{i}$ measures the heterogeneity distance between the public factor $\mu_{\mathrm{t}}$ and the system part $X_{\mathrm{it}}, \mu_{\mathrm{t}}$ represents the common behavior of $X_{i t}$ aggregation, which reflects the influence of individual behavior plus common factors. It should be pointed out that although the system term $\delta_{\mathrm{i}}$ expresses the heterogeneity of individuals, this heterogeneity does not change with time. Therefore, when considering the heterogeneity of individuals with time-varying characteristics, the following improvements are needed:

$$
X_{\mathrm{it}}=\delta_{\mathrm{it}} \mu_{\mathrm{t}}
$$

Among them, $\delta_{i t}$ expresses the change of individual heterogeneity with time, including the random component $\varepsilon_{i \mathrm{t}}$. Therefore, equation (2) contains the time-varying characteristics of individual heterogeneity and the common trend term of the system, which is the nonlinear time-varying factor model.

To model the time-varying parameter $\delta_{i t}$, we define a relative transfer coefficient:

$$
h_{i t}=\frac{x_{i t}}{N^{-1} \sum_{i=1}^{\mathrm{N}} x_{i t}}=\frac{\delta_{i t}}{N^{-1} \sum_{i=1}^{\mathrm{N}} \delta_{i t}}
$$




$$
\mathrm{H}_{\mathrm{t}}^{2}=\mathrm{N}^{-1} \sum_{\mathrm{i}=1}^{\mathrm{N}}\left(\mathrm{h}_{\mathrm{it}}-1\right)^{2}
$$

Specifically, the $\mathrm{h}_{\mathrm{it}}$ relative transfer coefficient, $\mathrm{H}_{\mathrm{t}}{ }^{2}$ is its variance. Since the common growth path, that is, the common factor portion is eliminated, when the convergence occurs, $\mathrm{h}_{\mathrm{it}} \rightarrow 1, \mathrm{H}_{\mathrm{t}}{ }^{2} \rightarrow 0$.

Further, in order to verify the null hypothesis of convergence, it is also necessary to construct a semi-parametric model:

$$
\delta_{i t}=\delta_{i}+\delta_{i} \zeta_{i t} / L(t) t^{-\alpha}
$$

where $\delta_{\mathrm{i}}$ is fixed and does not change with time $\mathrm{t} ; \sigma_{\mathrm{i}}$ is a heterogeneous scale parameter; $\xi_{\mathrm{it}}$ is subject to $\operatorname{iid}(0,1) ; \mathrm{L}(\mathrm{t})$ is a slowly changing function and when $\mathrm{t} \rightarrow \infty, \mathrm{L}(\mathrm{t}) \rightarrow \infty ; \alpha$ is the decay rate. The semi-parametric model shows that as long as $\alpha \geq 0$ is satisfied, $\delta_{i t} \rightarrow \delta_{i}$, that is, the convergence is established.

Based on the above derivation process, the null hypothesis of the test convergence can be written as follows:

$$
\begin{gathered}
\mathrm{H}_{0}: \delta_{\mathrm{i}}=\delta \text { and } \alpha \geq 0 \\
\mathrm{H}_{\mathrm{A}}: \delta_{\mathrm{i}} \neq \delta \text { or } \alpha<0
\end{gathered}
$$

In order to verify the original hypothesis of convergence, regression is performed using the following formula:

$$
\log \left(\frac{\mathrm{H}_{1}}{\mathrm{H}_{\mathrm{t}}}\right)-2 \log \mathrm{L}(\mathrm{t})=\mathrm{a}+\mathrm{b} \log \mathrm{t}+\mu_{\mathrm{t}}
$$

where $\mathrm{L}(\mathrm{t})=\log (\mathrm{t}+1) ; \mathrm{t}=[\gamma \mathrm{T}],[\gamma \mathrm{T}]+1, \ldots, \mathrm{T} ; \gamma$ is the parameter determining the starting time $\mathrm{t}$, according to Monte Carlo simulation experiment of Phillips and Sul. As a result, $\gamma=0.3$, a $=0.5 \mathrm{~b}$, and then heteroscedasticity and autocorrelation (HAC) one-sided T test. If $t_{b} \geq-1.65$, the null hypothesis cannot be rejected. Otherwise the null hypothesis is rejected. Since the above method utilizes a cross-sectional variance ratio to perform a linear regression of the logt time series, this convergent regression test is called a logt test.

\subsubsection{Convergence Club Identification Step Based on Logt Test}

When the null hypothesis of the convergence of all cities is rejected, it can be further identified according to the principle of logt test whether there is a convergence club. The identification method is an endogenous convergence club identification method. It is based entirely on urban-rural income disparity data for each city and is not based on any external criteria such as geographic zoning. The specific identification steps are as follows:

Step 1: Sort the individual segments. The basis is:

$$
(\mathrm{T}-[\mathrm{Ta}])^{-1} \sum_{\mathrm{t}=[\mathrm{Ta}]+1}^{\mathrm{T}} \mathrm{X}_{\mathrm{it}}, \mathrm{a}=1-\mathrm{f}
$$

The observations are sorted in descending order, and the time span $\mathrm{f}$ of the observations is selected. The value of $\mathrm{f}$ is chosen as $1 / 2$.

Step 2: Identify the initial core group. Select the first two cities in the results of step 1 and do the logt test. If the original hypothesis is rejected, the first city is removed, the second and third cities are grouped into new groups, and the logt test is performed. Repeat above processes until you find two cities that cannot reject the null hypothesis. These two cities are the initial core groups and jump to step 3. If you traverse all two cities, you can't find the initial core group, indicating that there are no converging clubs and all cities are not aligned with each other.

Step 3: Identify the new core group members. According to the ranks arranged in the first step, the cities that have not been inspected together with the initial core group members are added to the 
initial core group one by one for logt test. In order to cluster members of similar nature as much as possible, the standard $\mathrm{c}$ of the selected club is set. $\mathrm{c}$ will be significantly higher than the threshold of the convergence club -1.65 , generally recommended $c=0$. Here $c$ is chosen as 0 . According to this cycle, after traversing all cities, all members of the core group are identified, and one convergence club is obtained. Phillips recommends numerical simulations, selecting a $50 \%$ significance level for a sample of 20 or 50; a $40 \%$ significance level for a sample of 100 ; and a $20 \%$ significant level for a sample of 200. The significant level chosen in this paper is $20 \%$.

Step 4: Do a logt test on all cities that do not belong to the Convergence Club in Step 3. If you cannot reject the null hypothesis, then these cities are considered as a convergence club. If you reject the null hypothesis, repeat steps 1 through 3 . Circulate this until you can identify all existing convergence clubs.

Step 5: Convergence clubs formed according to the clustering process are carried out with the members entering the core group criteria. Therefore, at a significant level of $5 \%$, there may still be convergence between different clubs, which need to be combined to merge the clubs with $t_{k}>-1.65$ into one group. The specific integration methods are as follows:

The first is the column value. In the club group, you get M Convergence Clubs: Club1, ..., ClubM. A logt test is performed for every two adjacent clubs. Let $\mathrm{m}=1,2, \ldots, \mathrm{M}-1$, and obtain the tm value of the (M-1) group. The second is the combination: starting from the first group, if $t_{m}>-1.65$ is satisfied and $t_{m}>t_{m+1}$, the two groups are merged and the first step is repeated; if not, the remaining group remains as a single group.

\subsection{Identification of the Convergence Club}

\subsubsection{Judgment of Overall Convergence}

Before identifying the Convergence Club, the overall urban-to-urban income gap convergence was judged by performing logt tests on 274 prefecture-level cities in China. Using the methods and steps in Section 4.1, 274 cities were fitted to obtain the following estimation results.

$$
\begin{aligned}
\log \left(\frac{\mathrm{H}_{1}}{\mathrm{H}_{\mathrm{t}}}\right)-2 \log \mathrm{t}= & 0.4934-0.3163 \log \mathrm{t} \\
(5.34) & (-3.20)
\end{aligned}
$$

It can be seen that $b=-0.3163, t_{b}=-3.2$, far less than the convergence threshold of -1.65 at the significant level of $5 \%$. Therefore, there is no overall convergence in the urban-rural income gap in China. It is necessary to explore whether there is a region where economic growth converges to the club. According to the division standard of the National Bureau of Statistics for economic regions in 2011, the convergence test of the clubs in the four major economic zones of northeast, eastern, central and western regions was obtained with the regression results shown in Table 1. It can be found that there is a convergence of the urban-rural income gap in the northeastern region and the western region, while the eastern and central regions do not have the convergence of the urban-rural income gap. This shows that although the division of the traditional economic zone reflects the facts of urban and rural areas to some extent. The spatial correlations of the development of income gap can be identified, but it cannot accurately reflect the internal relationship and similarity of regional income gap between urban and rural areas. Only some economic regions can meet the criteria for judging the convergence of urban-rural income gap. The study of $X u$ and Zhang analyzed the dynamic evolution of urbanization and urban-rural income gap in China, as well as the spatiotemporal effects and differences of new urbanization on urban-rural income gap in China. It was found in this study that there is an obvious regional heterogeneity in the impact of urbanization transformation on urban-rural income gap. With the in-depth transformation of urbanization, the urban income gap in the eastern region is still significantly expanding, while the expansion trend in the central region is not obvious, and the expansion trend in the western region is restrained [25].The convergence of the income gap between urban and rural areas in the western region further verifies the conclusion of $\mathrm{Xu}$ and Zhang 
that the widening trend of the income gap between urban and rural areas in the western region has been restrained.

Table 1. Convergence test of the four major economic zones.

\begin{tabular}{cccc}
\hline Region & Provinces, Municipalities, Autonomous Regions & t Value & Convergence \\
\hline North-east area & Heilongjiang, Jilin, Liaoning & -0.73 & Yes \\
East area & Beijing, Tianjin, Hebei, Shanghai, Jiangsu, Zhejiang, & -3.40 & No \\
Central Region & Fujian, Shandong, Guangdong, Hainan & -6.30 & No \\
Shanxi, Anhui, Jiangxi, Henan, Hubei, Hunan & Yes \\
\hline
\end{tabular}

\subsubsection{Convergence Club Judgment}

(1) Divide 274 cities into 4 groups. If $\mathrm{t}>-1.65$, it means that the individual in the club has a convergence trend.

(2) Add the data of the remaining cities to the core group in turn. At this time, the $t$ value is increased from -1.65 to 0 , and there is still a possibility of convergence at the $20 \%$ significance level between the groups.

(3) Integrate the four groups according to the club integration method. The third largest convergence club for urban and rural income gaps in China was obtained (see Table 2 for detailed club convergence). On the surface of the inspection, the three clubs all showed significant convergence, and most of the cities were located in the first two clubs. According to the club rankings, the average urban-rural income gap of the club members showed a downward trend.

Table 2. China's urban and rural income gap convergence trend club group integration results.

\begin{tabular}{ccccccc}
\hline Club & Group & $\begin{array}{c}\text { Number of } \\
\text { Cities }\end{array}$ & Coefficient $\mathbf{b}$ & t Value & S.E. & $\begin{array}{c}\text { Mean of Urban-Rural } \\
\text { Income Gap }\end{array}$ \\
\hline Club1 & 1 & 167 & 0.2017 & 1.41 & 0.1427 & 2.8050 \\
Club2 & 2,3 & 85 & 0.3741 & 1.44 & 0.2606 & 2.2011 \\
Club3 & 4 & 5 & 0.3972 & 1.68 & 0.3972 & 2.1033 \\
Divergence & 5 & 17 & -1.3583 & -14.31 & 0.9494 & 2.5420 \\
\hline
\end{tabular}

\subsubsection{Analysis of Empirical Results}

Table 3 shows the distribution of convergence clubs in China's four major economic zones. In general, most cities in the western region are located in the first club. The cities in northeast region are mainly distributed in the First Club and the Second Club. The central and eastern regions are distributed in all three major clubs.

Table 3. Distribution of clubs in the four economic zones.

\begin{tabular}{ccc}
\hline Club & $\begin{array}{c}\text { Number of } \\
\text { Cities }\end{array}$ & Distribution Area \\
\hline Club1 & 167 & western region (67), central region (51), eastern region (34), northeastern region (15) \\
Club2 & 85 & eastern region (39), central region (27), northeastern region (11), western region (8) \\
Club3 & 5 & eastern region (3), central region (2) \\
\hline
\end{tabular}

It could be observed the variation coefficient of the urban-rural income gap among different clubs. As shown in Figure 2 below, we can clearly see that the coefficient of variation of urban-rural income gap among different clubs fluctuates constantly. Overall, we have experienced the process of expanding and then shrinking. Since 2009, the three clubs have shown a process of continuous convergence. It shows that the income gap between urban and rural areas within the club is constantly narrowing. 


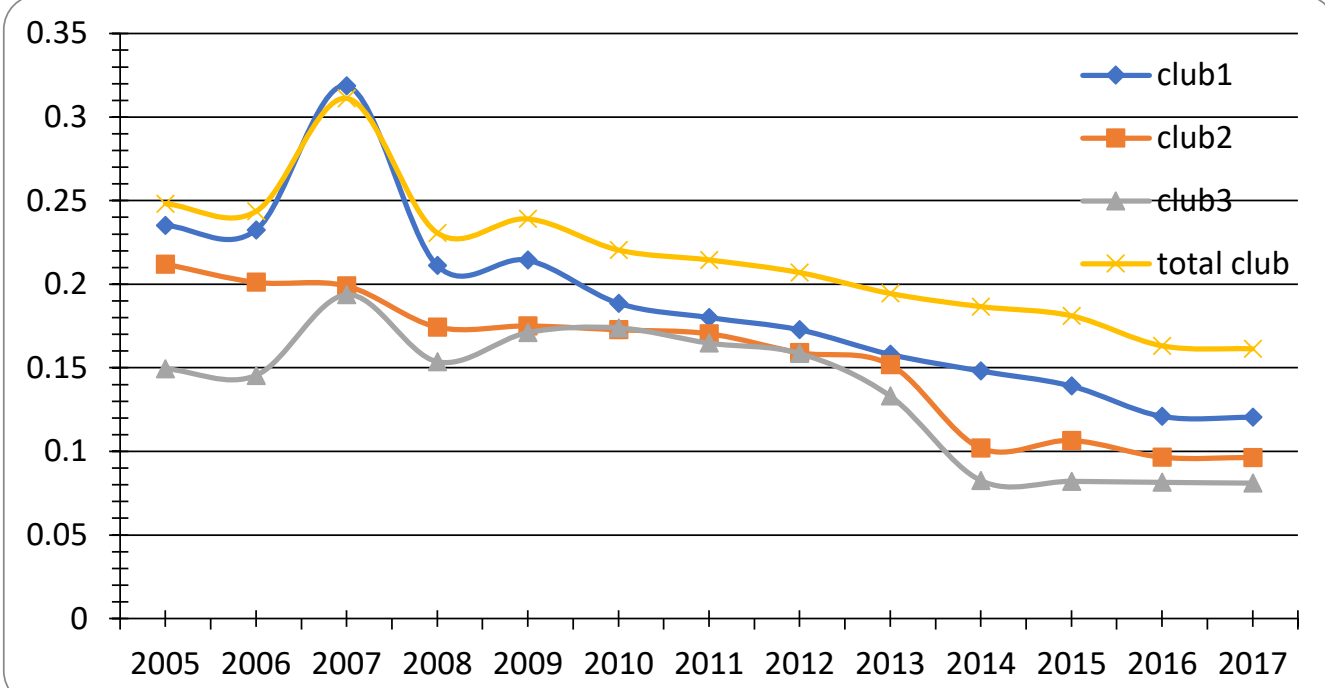

Figure 2. Coefficient of variation of urban-rural income gap among clubs.

\section{Causes of Club Convergence}

For studying further the factors affecting the urban and rural income gap club grouping, this paper will use the ordered logit model to conduct regression analysis on the club grouping and explore the effects of internal determinants of the urban-rural income gap convergence club formation.

\subsection{Variable Selection and Model Construction}

According to the needs of the empirical research and considering the availability of data, this paper selects: (1) The level of local economic development (devel), expressed by the per capita GDP of each city. The level of local economic development is an important influencing factor of social development, such as the urban-rural income gap. (2) The degree of local intervention (gbeha), measured by the ratio of local fiscal expenditure to local GDP. The degree of local intervention denotes the government management capacity, which is crucial to social development.(3)Foreign direct investment (fdi), measured by the proportion of actual use of foreign capital in GDP in the year of Chinese Yuan (CNY) conversion. The fdi reflects the openness of a city. It is the representative of the government performance. The fdi brings the introduction of foreign enterprises and causes the hiring of more employees. It determines the income levels of different residents. It is also an important factor of the urban-rural income gap. (4) High-speed rail effect ( $\mathrm{gt}$ ), measured by the number of high-speed railway stations opened. (5)The proportion of urban population to total population, measured by the level of urbanization(urb). Urbanization is an important factor that will influence the income gap between urban and rural residents.(6)The industrial structure, measured by the sum of the added value of the secondary industry and the added value of the tertiary industry as a percentage of GDP (ind). Industrial structure determines the income level of residents. It is an influencing factor for the income gap. The sample interval is from 2005 to 2016. The data mainly come from the Economy Prediction System (EPS) China database, the statistical yearbook of each city, the website of the China Railway Corporation, the news reports or announcements of the National Railway Administration, and the website of the China Railway Corporation 12306. All the data except devel and gtare relative indexes. To avoid the difference of units, the variable devel is calculated with 10,000 RMB.Here we focus on the High-speed railway effect on the urban-rural income gap. Based on the literature review and above analysis, the hypotheses are constructed as follows:

Hypothesis 1. High-speed railway effect of urban-rural income gap is significant. 
Hypothesis 2. High-speed railway effect of convergence of urban-rural income gap is significant.

According to the regression results estimated by the panel fixed effect model, as shown in Table 4, we have determined the influencing factors of the urban-rural income gap. It can be seen that the regression coefficient is negative and significant at $1 \%$ level. The results shows High-speed railway effect (gt) have significant negative effects on the urban-rural income gap. It shows the hypothesis 1 is correct. High-speed railway effect of urban-rural income gap is significant. Besides, foreign direct investment (fdi), local economic development level (devel), and urbanization rate (urb) also have significant negative effects on the urban-rural income gap. In other words, the construction of High-speed railway, foreign direct investment, urbanization, and the improvement of regional development levels are conducive to narrowing the urban-rural income gap in China. The degree of local intervention (gbeha) and industrial structure changes (ind) have significant positive effects on the urban-rural income gap. It can be found that the intervention of local governments is an important factor in expanding the urban-rural income gap in China. Moreover, the industrial structure upgrade has widened the urban-rural income gap.

Table 4. Fixed effect model regression results.

\begin{tabular}{|c|c|c|c|c|}
\hline Model & 1 & 2 & 3 & 4 \\
\hline devel & $\begin{array}{c}-0.0762359^{* * * *} \\
(0.0046241)\end{array}$ & $\begin{array}{c}-0.067033^{* * *} \\
(0.0045977)\end{array}$ & $\begin{array}{c}-0.0620697^{* * *} \\
(0.0046505)\end{array}$ & $\begin{array}{c}-0.0631602^{* * *} \\
(0.0050142)\end{array}$ \\
\hline urb & $\begin{array}{c}-0.2297582^{* * *} \\
(0.0484925)\end{array}$ & $\begin{array}{c}-0.1480799^{* * *} \\
(0.0489607)\end{array}$ & $\begin{array}{c}-0.1391756^{* * *} \\
(0.0487126)\end{array}$ & $\begin{array}{c}-0.2171518^{* * *} \\
(0.0499533)\end{array}$ \\
\hline gt & $\begin{array}{c}-0.0634502^{* * *} \\
(0.0196414)\end{array}$ & $\begin{array}{c}-0.0520909^{* * * *} \\
(0.0192339)\end{array}$ & $\begin{array}{c}-0.0686494^{* * *} \\
(0.0193361)\end{array}$ & $\begin{array}{c}-0.0683473^{* * * *} \\
(0.0191887)\end{array}$ \\
\hline fdi & & $\begin{array}{c}-4.840153^{* * *} \\
(0.5251888)\end{array}$ & $\begin{array}{c}-4.290662^{* * *} \\
(0.5306807)\end{array}$ & $\begin{array}{c}-4.351761^{* * *} \\
(0.5274679)\end{array}$ \\
\hline gebha & & & $\begin{array}{c}0.8348368^{* * * *} \\
(0.1429672)\end{array}$ & $\begin{array}{l}0.9678393^{* * *} \\
(0.1452194)\end{array}$ \\
\hline ind & & & & $\begin{array}{c}0.3343478^{* * *} \\
(0.1278829)\end{array}$ \\
\hline _cons & $\begin{array}{l}2.984747^{* * *} \\
(0.0206154)\end{array}$ & $\begin{array}{l}3.009603^{* * *} \\
(0.0211706)\end{array}$ & $\begin{array}{l}2.851538^{* * *} \\
(0.0342922)\end{array}$ & $\begin{array}{l}2.569233^{* * * *} \\
(0.1102339)\end{array}$ \\
\hline Prob $>$ F & 0.0000 & 0.0000 & 0.0000 & 0.0000 \\
\hline
\end{tabular}

We use the indicators that significantly affect the urban-rural income gap in the above regression analysis as the independent variables of the ordered logit model. Then the ranked logit regression method is used to test the factors that affect the three major convergence clubs. The club categories (club1 club3) as explained variables are ordered discrete variables. In this paper, ordered logit model is used to explain the mechanism of club classification. Through the model analysis of various factors on the probability of the formation of convergence club. In this paper, the club's category value is 1, 2, 3 , the model is set as follows:

$$
Y^{*}=x^{\prime} \beta+\varepsilon
$$

Among them, $\mathrm{y}^{*}$ is the latent variable corresponding to the explained variable "club category $(\mathrm{y})$ ". $x^{\prime}$ is the set of explained variables, including devel, gbeha, fci, gt, urb and ind. $\beta$ is the parameter to be estimated. $\varepsilon$ is the random disturbance term. Its selection rules meet the following conditions:

$$
y=\left\{\begin{array}{cc}
1 & y^{*} \geq a_{0} \\
2 & a_{0} \leq y^{*} \leq a_{1} \\
3 & y^{*} \geq a_{1}
\end{array}\right.
$$


Among them, $\alpha_{0}<\alpha_{1}<\alpha_{2}$ is the parameter to be estimated, also known as threshold or cut. $y$ is the rating score, which is $1,2,3$. y represents the category of the club. For example, $y=1$ represents club1. If $\beta>0$, with the increase of $x^{\prime}$, the probability of $y^{*}$ in the higher category will increase, which means that the category of the club will increase. Based on this, the probability effect of each independent variable on the observation value $y$ of the dependent variable can be calculated.

\subsection{Empirical Results and Discussion}

Table 5 shows the orderd logit model parameter estimation results with $\mathrm{y}^{*}$ as the dependent variable. It can be seen that $\mathrm{fdi}$, indand gebha have a significant effect on the latent variable $\mathrm{y}^{*}$. The estimated $\beta$ of fdi is 11.6 , which is significantly positively correlated at the $1 \%$ level. The estimated value of $\beta$ for gebha is -3.957 , which is significantly negatively correlated at the $1 \%$ level. The estimated value of $\beta$ for ind is -1.275 , which is significantly negatively correlated at the $5 \%$ level.The independent variables gt, devel, and urb have no significant effect on the latent variable $y^{*}$. In other words, although the construction of High-speed railway, the improvement of regional development level and urbanization can effectively reduce the urban-rural income gap between cities, it is not an important factor in forming the three convergence clubs. It shows hypothesis 2 is not correct. High-speed railway effect of convergence of urban-rural income gap is not significant. This indicates that the current impact of China's High-speed railway construction on the urban-rural income gap is relatively weak compared to the impact of local government intervention and foreign direct investment.

Table 5. Estimation results of the ordered logit model.

\begin{tabular}{|c|c|c|c|c|c|c|c|}
\hline Club & Coef. & St.Err. & t-Value & p-Value & {$[95 \%$ Conf } & Interval] & Sig \\
\hline gt & 0.035 & 0.073 & 0.48 & 0.634 & -0.109 & 0.179 & \\
\hline fdi & 11.738 & 1.963 & 5.98 & 0.000 & 7.892 & 15.585 & $* * *$ \\
\hline gdp & 0.021 & 0.019 & 1.11 & 0.268 & -0.016 & 0.058 & \\
\hline gebha & -4.500 & 0.685 & -6.57 & 0.000 & -5.842 & -3.158 & $* * *$ \\
\hline $\mathrm{czl}$ & 0.173 & 0.195 & 0.89 & 0.374 & -0.209 & 0.556 & \\
\hline ind & -1.275 & 0.502 & -2.54 & 0.011 & -2.259 & -0.292 & $* *$ \\
\hline cut1 & -0.793 & 0.440 &.$b$ &.$b$ & -1.655 & 0.068 & \\
\hline cut2 & 2.539 & 0.456 &.$b$ &.$b$ & 1.646 & 3.433 & \\
\hline
\end{tabular}

It should be pointed out that since the ordered logit regression uses the maximum likelihood method to estimate the regression coefficient, the size of the above regression coefficient does not have the meaning of the marginal effect, and the direction of the influence of the variable on the interpreted variable can only be explained according to its symbol analysis. Further exploration of the marginal effects of each influencing factor on the probability of each club is shown in Table 6 .

According to the estimation results in Table 6, it can be seen that with the increase of foreign investment, the possibility of the city belonging to the club1 will decrease, and the possibility of belonging to the club2 and club3 will increase. As the level of local government intervention increases and the industrial structure upgrades, the possibility of the city belonging to the club1 will increase, and the possibility of belonging to the club2 and club3 will increase. In other words, foreign investment will help cities converge to clubs with lower average urban-rural income gaps. Local government intervention and industrial structure upgrade will promote cities to converge to clubs with high average urban-rural income gap. 
Table 6. Average marginal effect results of the ordered logit model.

\begin{tabular}{ccccccc}
\hline & dy/dx & Std.Err. & $\mathbf{z}$ & $\mathbf{P}>\mathbf{z}$ & [95\%Conf. & Interval] \\
\hline fdi & & & & & & \\
_predict & & & & & & \\
1 & -2.582 & 0.422 & -6.12 & 0 & -3.409 & -1.755 \\
2 & 2.348 & 0.383 & 6.13 & 0 & 1.597 & 3.098 \\
3 & 0.234 & 0.049 & 4.76 & 0 & 0.138 & 0.331 \\
\hline gebha & & & & & & \\
predict & & & & & & \\
1 & 0.99 & 0.147 & 6.73 & 0 & 0.702 & 1.278 \\
2 & -0.9 & 0.134 & -6.74 & 0 & -1.162 & -0.638 \\
3 & -0.09 & 0.018 & -5.07 & 0 & -0.125 & -0.055 \\
\hline ind & & & & & & \\
-Predict & & & & & & \\
1 & 0.281 & 0.11 & 2.55 & 0.011 & 0.065 & 0.496 \\
2 & -0.255 & 0.1 & -2.55 & 0.011 & -0.451 & -0.059 \\
3 & -0.025 & 0.011 & -2.41 & 0.016 & -0.046 & -0.005 \\
\hline
\end{tabular}

\section{Conclusions}

Since the reform and opening up, China's economy has shifted from high-speed development to a new normal of medium-to-high-speed growth in the latter period [46]. Whether China can cross the current middle-income trap after the economic slowdown and achieve regional coordinated development is still a puzzle. Exploring the convergence of urban-rural income gaps can provide a basis for the formulation of national and regional industrial policies.

This paper examines the urban-rural income gap of prefecture-level cities from 2005 to 2016 through the nonlinear time-varying factor model for automatic identification and grouping, then tests the conditions and internal mechanisms that determine the convergence of urban-rural income gaps. This study found the following results: In the traditional four economic regions of China, the convergence of urban-rural income gap exists in the northeast and the west, while the convergence of urban-rural income gap does not exist in the east and the middle. Although the division of traditional economic zones reflects the spatial correlation of the development of urban-rural income gap to some extent, and it cannot accurately reflect the internal relationship and similarity of the change of regional urban-rural income gap. Only some economic zones meet the criteria of convergence of urban-rural income gap. However, cities are divided into three major convergence clubs by logt test. The eastern and central regions are scattered in three clubs. The western region and the northeast region are concentrated in the largest club.

Secondly, the construction of High-speed railway has effectively narrows the urban-rural income gap in China, but it is not the cause of the formation of the three convergence clubs. The convergence effect of High-speed railway on the urban-rural income gap in China is still relatively weak. Related research shows that the impact of High-speed railway on urban economic growth is relatively lagging behind. Moreover, in some cities, the opening time of the High-speed railway is relatively late, and the role has not yet appeared. Therefore, the sample data still has certain limitations.

Thirdly, foreign direct investment promotes cities to converge to high-class clubs with lower average urban-rural income gap. Local government intervention and industrial structure upgrades will promote cities to converge to low-class clubs with higher average urban-rural income gap.

Based on the above research conclusions, we propose the following policy recommendations. In the construction of High-speed railway, it is necessary to carry out overall planning considering the changes of the industrial structure and the equalization of welfare. Providing farmers with supporting policies and other opportunities to enable the High-speed railway to bring better urban back-feeding effects and narrow the urban-rural income gap. The government needs to reverse the urban bias policy in terms of fiscal expenditure and investment. To achieve coordinate development in urban and rural 
areas, China's government should provide more infrastructure construction and financial investment in education, healthcare, social security or other social undertakings in rural areas.

Author Contributions: Conceptualization, W.L.; Methodology, W.L. and X.W.; Software, X.W.; Validation, W.L., O.-P.H. and X.W.; Formal Analysis, W.L., X.W. and O.-P.H.; Investigation, W.L., O.-P.H. and X.W.; Resources, W.L., O.-P.H.; Data Curation, W.L. and X.W.; Writing-Original Draft Preparation, W.L.,X.W.; Writing-review \& Editing, W.L., O.-P.H. and X.W.; Visualization, X.W.; Supervision, W.L., O.-P.H..; Funding acquisition, W.L.; Project Administration, W.L.. All authors have read and agreed to the published version of the manuscript.

Funding: This research was funded by the China National Key Research and Development Plan, grant number 2018YFB1201400.

Conflicts of Interest: The authors declare no conflict of interest.

\section{References}

1. National Statistical Bureau. China's Statistical Yearbook 2018; China Statistics Press: Beijing, China, 2018.

2. Chen, F.; Xu, K.; Wang, M. The development of high-speed rail and the income gap between urban and rural residents: Evidence from Chinese cities. Econ. Rev. 2018, 2, 59-73.

3. National Railway Bureau. Introduction of HSR Economics; China Railway Publishing House: Beijing, China, 2018.

4. Zhang, A.; Wan, Y.; Yang, H. Impacts of high-speed rail on airlines, airports and regional economies: A survey of recent research. Transp. Policy 2019, 81, A1-A19. [CrossRef]

5. Chai, J.; Zhou, Y.; Zhou, X.; Wang, S.; Zhang, Z.G.; Liu, Z. Analysis on shock effect of China's high-speed railway on aviation transport. Transp. Res. Part. A: Policy Pract. 2018, 108, 35-44. [CrossRef]

6. Liu, L.; Zhang, M. High-speed rail impacts on travel times, accessibility, and economic productivity: A benchmarking analysis in city-cluster regions of China. J. Transp. Geogr. 2018, 73, 25-40. [CrossRef]

7. Li, H.; Strauss, J.; Shunxiang, H.; Lui, L. Do high-speed railways lead to urban economic growth in China? A panel data study of China's cities. Q. Rev. Econ. Financ. 2018, 69, 70-89. [CrossRef]

8. Vickerman, R. Can high-speed rail have a transformative effect on the economy? Transp. Policy 2017, 62, 31-37. [CrossRef]

9. Li, X.; Huang, B.; Li, R.; Zhang, Y. Exploring the impact of high speed railways on the spatial redistribution of economic activities-Yangtze River Delta urban agglomeration as a case study. J. Transp. Geogr. 2016, 57, 194-206. [CrossRef]

10. Jia, S.; Zhou, C.; Qin, C. No difference in effect of high-speed rail on regional economic growth based on match effect perspective? Transp. Res. Part. A: Policy Pract. 2017, 106, 144-157. [CrossRef]

11. Ke, X.; Chen, H.; Hong, Y.; Hsiao, C. Do China's high-speed-rail projects promote local economy? New evidence from a panel data approach. China Econ. Rev. 2017, 44, 203-226. [CrossRef]

12. Lynch, T.A.; Sipe, N.; Polzin, S.E.; Chu, S.E. An analysis of the economic impacts of Florida high speed rail. Employment 1997, 8, 1-16.

13. Masson, S.; Petiot, R. Can the high speed rail reinforce tourism attractiveness? The case of the high speed rail between Perpignan (France) and Barcelona (Spain). Technovation 2009, 29, 611-617. [CrossRef]

14. Diao, M. Does growth follow the rail? The potential impact of high-speed rail on the economic geography of China. Transp. Res. Part. A: Policy Pract. 2018, 113, 279-290. [CrossRef]

15. Chen, C.L.; Hall, P. The impacts of high-speed trains on British economic geography: A study of the UK's InterCity 126/226 and its effects. J. Transp. Geogr. 2011, 19, 689-706. [CrossRef]

16. Sasaki, K.; Ohashi, T.; Ando, A. High-speed rail transit impact on regional systems: Does the Shinkansen contribute to dispersion? Ann. Reg. Sci. 1997, 31, 77-98. [CrossRef]

17. Chen, Z.; Xue, J.; Rose, A.Z.; Haynes, K.E. The impact of high-speed rail investment on economic and environmental change in China: A dynamic CGE analysis. Transp. Res. Part. A Policy Pract. 2016, 92, 232-245. [CrossRef]

18. Preston, J.; Wall, G. The Ex-ante and Ex-post Economic and Social Impacts of the Introduction of High-speed Trains in South East England. Plan. Pract. Res. 2008, 23, 403-422. [CrossRef]

19. Chen, Z.; Haynes, K.E. Impact of high-speed rail on regional economic disparity in China. J. Transp. Geogr. 2017, 65, 80-91. 
20. Jiang, M.; Kim, E. Impact of high-speed railroad on regional income inequalities in China and Korea. J. Int. J. Urban. Sci. 2016, 20, 393-406. [CrossRef]

21. Wang, Y.; Tang, S.; Huang, Y.; Bai, S. Analysis of the effect of urbanization promoting the convergence of urban and rural income gap-Based on the empirical test of 71 counties in Wuling mountain area. Mod. Manag. Sci. 2016, 6, 42-44.

22. Deng, J. Does urbanization and industrialization promote the convergence of urban and rural income gaps? An Empirical Test Based on Panel Threshold Model. Hanjiang Acad. 2016, 35, 78-84.

23. Song, J.; Wang, J. Dynamic convergence analysis of population migration, household registration urbanization and urban-rural income gap-Evidence from 262 prefecture-level cities. Popul. J. 2018, 40, 86-99.

24. $\mathrm{Wu}, \mathrm{H}$. Research on the convergence of urban-rural income gap in China-Based on the perspective of government investment. East China Econ. Manag. 2019, 33, 115-121.

25. Xu, J.; Zhang, D. The Transformation of urbanization and the convergence of income gap between urban and rural areas in China. Reg. Res. Dev. 2019, 38, 17-21.

26. Bartkowska, M.; Riedl, A. Regional convergence clubs in Europe: Identification and conditioning factors. Econ. Model. 2012, 29, 22-31. [CrossRef]

27. Canova, F. Testing for convergence clubs in income per capita: A predictive density approach. Int. Econ. Rev. 2004, 45, 49-77. [CrossRef]

28. Galor, O. Multiple growth regimes-Insights from unified growth theory. J. Macroecon. 2007, 29, 470-475. [CrossRef]

29. Tian, X.; Zhang, X.; Zhou, Y.; Yu, X. Regional income inequality in China revisited: A perspective from club convergence. Econ. Model. 2016, 56, 50-58. [CrossRef]

30. Wang, Y.F.; Yang, H.B.; Tang, S. The function mechanism and dynamic analysis of urbanization and industrial structure adjustment to urban-rural income gap. Mod. Econ. Manag. 2015, 3, 56-63.

31. Sun, F.; Mansury, Y.S. Economic Impact of High-Speed Rail on Household Income in China. Transp. Res. Rec. J. Transp. Res. Board 2016, 2581, 71-78. [CrossRef]

32. Vickerman, R. High-speed rail and regional development: The case of intermediate stations. J. Transp. Geogr. 2015, 42, 157-165. [CrossRef]

33. Wang, F.; Wei, X.; Liu, J.; He, L.; Gao, M. Impact of high-speed rail on population mobility and urbanisation: A case study on Yangtze River Delta urban agglomeration, China. Transp. Res. Part. A: Policy Pract. 2019, 127, 99-114. [CrossRef]

34. Pan, X.; Liu, Q.; Peng, X. Spatial club convergence of regional energy efficiency in China. Ecol. Indic. 2015, 51, 25-30. [CrossRef]

35. Ivanovski, K.; Churchill, S.A.; Smyth, R. A club convergence analysis of per capita energy consumption across Australian regions and sectors. Energy Econ. 2018, 76, 519-531. [CrossRef]

36. Khan, H.U.; Siddique, M.; Zaman, K.; Yousaf, S.U.; Shoukry, A.M.; Gani, S.; Sasmoko; Khanj, A.; Hishan, S.S.; Saleem, H. The impact of air transportation, railways transportation, and port container traffic on energy demand, customs duty, and economic growth: Evidence from a panel of low-, middle-, and high-income countries. J. Air Transp. Manag. 2018, 70, 18-35. [CrossRef]

37. Wang, S.; Tan, S.; Yang, S.; Lin, Q.; Zhang, L. Urban-biased land development policy and the urban-rural income gap: Evidence from Hubei Province, China. Land Use Policy 2019, 87, 91-103. [CrossRef]

38. Su, C.W.; Liu, T.Y.; Chang, H.L.; Jiang, X.Z. Is urbanization narrowing the urban-rural income gap? A cross-regional study of China. Habitat Int. 2015, 48, 79-86. [CrossRef]

39. Li, Y.; Wang, X.; Zhu, Q.; Zhao, H. Assessing the spatial and temporal differences in the impacts of factor allocation and urbanization on urban-rural income disparity in China, 2004-2010. Habitat Int. 2014, 42, 76-82. [CrossRef]

40. Mora, T.; Vayá, E.; Suriñach, J. Specialisation and growth: The detection of European regional convergence clubs. Econ. Lett. 2005, 86, 181-185. [CrossRef]

41. Li, R.; Pantelous, A.A.; Yang, L. Robust analysis for premium-reserve models in a stochastic nonlinear discrete-time varying framework. J. Comput. Appl. Math. 2020, 368, 112592. [CrossRef]

42. Solow, R.M. A contribution to the theory of economic growth. Q. J. Econ. 1956, 70, 65-94. [CrossRef]

43. Baumol, W.J. Productivity growth, convergence, and welfare: What the long-run data show. Am. Econ. Rev. 1986, 76, 1072-1085. 
44. Peter, C.B.P.; Sul, D. Transition Modeling and Econometric Convergence Tests. Econometrica 2007, 75, 1771-1855.

45. Yu, Y.; Pan, Y. Has the opening of high-speed rail narrowed the income gap between urban and rural areas? An explanation from the perspective of Heterogeneous Labor Transfer. China's Rural Econ. 2019, 1, 79-95.

46. Li, W.; Hilmola, O.-P.; Wu, J. Chinese High-Speed Railway: Efficiency Comparison and the Future. PROMET Traffic Transp. J. 2019, 31, 693-702. [CrossRef]

(c) (1)

(C) 2020 by the authors. Licensee MDPI, Basel, Switzerland. This article is an open access article distributed under the terms and conditions of the Creative Commons Attribution (CC BY) license (http://creativecommons.org/licenses/by/4.0/). 